\title{
INFLUÊNCIA DA ALTITUDE NA QUALIDADE DAS UVAS 'CHARDONNAY' E 'PINOT NOIR' EM MINAS GERAIS'
}

\author{
MURILLO DE ALBUQUERQUE REGINA², EZEQUIEL LOPES DO CARMO ${ }^{3}$, \\ ANDERSON RIDOLFI FONSECA ${ }^{4}$, EDUARDO PURGATTO 5 , TÂNIA MISUZU SHIGA ${ }^{6}$, \\ FRANCO MARIA LAJOLO ${ }^{7}$, ANA PAULA RIBEIRO $^{8}$, RENATA VIEIRA DA MOTA $^{9}$
}

RESUMO - No Sul e Sudeste brasileiros, o excesso de chuvas durante o período de maturação afeta negativamente a qualidade dos vinhos tintos. Por outro lado, estas regiões possuem potencial para a elaboração de espumantes, uma vez que, para a elaboração desta bebida, a uva é colhida antes de completar o amadurecimento. No Estado de Minas Gerais, as condições de verão chuvoso estão presentes em todas as regiões de potencial vitícola, e a variação de altitude entre elas pode exercer influência na composição das uvas. Desta forma, este estudo buscou avaliar o potencial de maturação de uvas 'Chardonnay' e 'Pinot Noir' destinadas à elaboração de espumantes em dois locais de Minas Gerais: Cordislândia (873m) e Caldas $(1.150 \mathrm{~m})$. As plantas foram enxertadas sobre 1.103 Paulsen e conduzidas em espaldeira. Foram avaliados os teores de sólidos solúveis totais, acidez total, ácidos málico e tartárico, e pH do mosto, tamanho e massa das bagas, compostos fenólicos nas cascas e sementes, antocianinas na casca e açúcares solúveis nas bagas, em duas safras consecutivas. As bagas apresentaram maior tamanho e massa quando cultivadas em Caldas. As uvas colhidas em Cordislândia apresentaram maior grau de maturação, sendo observados maior $\mathrm{pH}$, maiores teores de glicose e frutose, e quantidade inferior de acidez e fenólicos totais nas sementes. Os maiores teores de ácido málico presentes nas uvas provenientes de Caldas sugerem que esta região pode ser mais indicada à produção de uvas para elaboração de vinhos espumantes.

Termos para indexação: Vitis vinifera; composição; vinho espumante; terroir; maturação.

\section{ALTITUDE INFLUENCE ON THE QUALITY OF 'CHARDONNAY'AND 'PINOT NOIR' GRAPES IN THE STATE OF MINAS GERAIS}

\begin{abstract}
In the southern and southeastern of Brazil, the excessive rainfall during the maturation period negatively affects the quality of red wines. On the other hand, these regions have great potential for the development of sparklings since that for the elaboration of this drink, the grape is harvested before complete its maturation. In the state of Minas Gerais, the conditions of rainy summer season are present in all regions of grape production potential, and the altitude variation between them influence on the grapes composition. Therefore, this study sought to evaluate the potential for maturing of the grapes 'Chardonnay' and 'Pinot Noir' which are designated for the preparation of sparklings in two locations of Minas Gerais: Cordislândia $(873 \mathrm{~m})$ and Caldas $(1150 \mathrm{~m})$. The plants were grafted on 1103 Paulsen and conducted in vertical shoot position trellis. It was evaluated the contents of total soluble solids, total acidity, malic and tartaric acid, and $\mathrm{pH}$ of the must, size and mass of the berries, phenolic compounds in the peels and in the seeds, anthocyanins in the peels and soluble sugars in the berries in two growing seasons. The berries had higher size and mass when grown in Caldas. The grapes harvested in Cordislândia presented a higher maturity degree, and it was observed a higher $\mathrm{pH}$, higher levels of glucose and fructose, and a lower amount of acidity and total phenolic content in the seeds. The highest levels of malic acid present in the grapes of Caldas suggest that this region may be more appropriate for the production of grapes which are used for making sparklings.

Index terms: Vitis vinifera, composition, sparkling wine, terroir, maturation.
\end{abstract}

'(Trabalho 045-09). Recebido em: 17-02-2009. Aceito para publicação em: 18-08-2009.

${ }^{2}$ Eng. Agr., Dr. em Viticultura e Enologia, Pesquisador do Núcleo Tecnológico EPAMIG Uva e Vinho, Caldas-MG. E-mail: murillo@epamigcaldas.gov.br

${ }^{3}$ Graduação em Engenharia Agronômica, Bolsista de Iniciação Tecnológica Industrial pelo CNPq. E-mail: pacaraima@bol.com.br

${ }^{4}$ Aluno de nível secundário, Bolsista de Iniciação Tecnológica Industrial pelo CNPq. E-mail: link@epamigcaldas.gov.br

${ }^{5}$ Farmacêutico, Dr. em Ciência dos Alimentos, Prof. do Dept ${ }^{\circ}$ de Alimentos e Nutrição Experimental, Faculdade de Ciências Farmacêuticas, Universidade de São Paulo, São Paulo-SP. e-mail: epurgatt@usp.br

${ }^{6}$ Farmacêutica, Dra. em Ciência dos Alimentos, Técnica de nível superior no Dept ${ }^{\circ}$ de Alimentos e Nutrição Experimental, Faculdade de Ciências Farmacêuticas, Universidade de São Paulo, São Paulo-SP. e-mail: tatymish@usp.br

${ }^{7}$ Farmacêutico Bioquímico, Doutor em Ciência dos Alimentos, Professor Titular do Departamento de Alimentos e Nutrição Experimental, Faculdade de Ciências Farmacêuticas, Universidade de São Paulo, São Paulo-SP. e-mail: fmlajolo@usp.br

${ }^{8}$ Biotecnologista, Bolsista de Apoio Técnico pela Fapemig. E-mail: anapaula@epamigcaldas.gov.br

${ }^{9}$ Eng $^{\mathrm{a}}$ Agr ${ }^{\mathrm{a}}$, Dra. em Ciência dos Alimentos, Pesquisadora do Núcleo Tecnológico EPAMIG Uva e Vinho, C. P. 33, Cep: 37780-000, Caldas-MG. E-mail: renata@epamigcaldas.gov.br (Autor para correspondência) 


\section{INTRODUÇÃO}

A produção nacional de uvas e a elaboração de vinhos apresentaram taxas significativas de crescimento nos últimos anos. O Rio Grande do Sul continua sendo o principal Estado produtor de uvas para vinificação, entretanto novas regiões surgem como polos produtores, como São Joaquim (SC), Petrolina (PE), Três Corações, Cordislândia e Pirapora (MG) (Protas et al., 2006).

Via de regra, nas regiões Sul e Sudeste brasileiras, onde o ciclo da videira ocorre uma só vez por ano e é determinado fundamentalmente pelas temperaturas ambientais, o período de maturação coincide com o período chuvoso, afetando o acúmulo de açúcares, a redução dos ácidos orgânicos e a maturação fenólica da uva, originando assim vinhos pouco encorpados, de pouca expressão varietal e com poucas condições de envelhecimento. Estas condições, entretanto, não impedem a produção de espumantes de qualidade, uma vez que a maturação da película das bagas não é indispensável no processo de elaboração desses vinhos, e o equilíbrio entre açúcares e ácidos das uvas, com menor índice de maturação, é favorável à apreciação sensorial dos mesmos.

Em Minas Gerais, as condições de verão chuvoso estão presentes em todas as regiões de potencial vitícola, e a variação de altitude entre elas pode exercer influência no potencial qualitativo das uvas. Johnson \& Nagel (1976) observaram que vinhos produzidos em Washington apresentaram teores de acidez titulável, $\mathrm{pH}$ e ácido málico superiores aos vinhos produzidos na Califórnia a partir das mesmas variedades. Os autores atribuíram estas diferenças à latitude dos dois estados produtores, uma vez que as uvas cultivadas em Washington foram submetidas a condições de temperatura mais baixa e maior intensidade de radiação solar.

Jackson \& Lombard (1993) citam que fatores como estrutura do solo, disponibilidade hídrica, manejo de pragas, condições macroclimáticas (latitude, altitude e topografia) e manejo do dossel exercem tanta influência sobre a composição das bagas quanto o genótipo (cultivar e porta-enxerto).

Apesar de possuir condições climáticas semelhantes às outras regiões vitícolas que se destacam na produção de vinhos espumantes, Minas Gerais ainda não produz este tipo de bebida. Seu potencial para a elaboração de espumantes é, entretanto, muito grande se considerarmos as condições climáticas das regiões vitícolas do sul de Minas Gerais e ainda as vantagens comparativas da localização do Estado em relação aos grandes centros consumidores do Brasil. Além disso, o último diagnóstico vitivinícola do sul de Minas Gerais, realizado pela Empresa de Pesquisa Agropecuária de Minas Gerais e Universidade Federal de Lavras (Silva, 1998) e o diagnóstico agronômico dos vinhedos de Caldas (Regina et al., 1998), apontam para urgente necessidade da busca de alternativas para este setor de forma a melhorar a qualidade dos vinhos produzidos e manter-se competitivo.

Este estudo buscou avaliar o potencial de maturação de uvas 'Chardonnay' e 'Pinot Noir' destinadas à elaboração de espumantes em dois locais de Minas Gerais: Cordislândia, a uma altitude de $873 \mathrm{~m}$, e Caldas a $1.150 \mathrm{~m}$.

\section{MATERIAL E MÉTODOS}

Foram avaliadas as cultivares Chardonnay e Pinot Noir cultivadas em vinhedos localizados nos municípios de Caldas e Cordislândia. As vinhas, com 4 anos de idade, foram formadas com mudas provenientes da França, enxertadas sobre o porta-enxerto 1103 Paulsen, conduzidas em espaldeira com três fios de arame e podadas em duplo cordão esporonado (sistema Royat). O espaçamento empregado foi de $2,5 \mathrm{x}$ 1,5 metros. A parcela experimental foi representada por 300 plantas para cada cultivar.

A localização geográfica e os dados climáticos destas regiões encontram-se na Tabela 1 .

Durante o amadurecimento, foram amostradas, semanalmente, 210 bagas por cultivar de forma aleatória na parcela experimental. As bagas, colhidas nas porções superior, inferior, mediana interna e externa do cacho, foram separadas em três repetições, e o mosto, extraído por prensagem manual. O mosto foi avaliado quanto aos teores de sólidos solúveis totais em refratômetro digital portátil ATAGO, modelo Pal-1, pH em pHmetro Micronal modelo B 474, calibrado com padrões 4,0 e 7,0, e acidez total por titulação com hidróxido de sódio $0,1 \mathrm{~N}$, utilizando fenolftaleína como indicador. $\mathrm{Na}$ colheita, foram avaliados os diâmetros transversal e longitudinal das bagas em paquímetro manual, a massa média de 100 bagas, $\mathrm{pH}$, sólidos solúveis e acidez total do mosto.

Para análise dos compostos fenólicos, foram separadas as cascas e as sementes de 100 bagas para cada tratamento. Aproximadamente $0,5 \mathrm{~g}$ de casca triturada em nitrogênio líquido foi homogeneizada em Ultra Turrax (IKA T-18 basic) em solução extratora constituída de metanol acidificado ( $\mathrm{HCl} 1 \%)$. As amostras permaneceram $12 \mathrm{~h} \mathrm{a} 4^{\circ} \mathrm{C}$, sendo em seguida centrifugadas ( $7.000 \mathrm{rpm}$ por $10 \mathrm{~min})$, e o pre- 
cipitado, lavado com solução extratora até a completa remoção da cor. Os sobrenadantes foram reunidos, e o volume, ajustado com solução extratora em balão volumétrico. As antocianinas foram determinadas pelo método do $\mathrm{pH}$ diferencial (Giusti \& Wrolstad, 2000) e expressas em mg malvidina-3-glicosídeo.g casca $^{-1}$. Os fenólicos totais foram analisados pelo método de Folin-Ciocalteau com base em uma curva-padrão de ácido gálico (Amerine \& Ough, 1980; Bergqvist et al., 2001).

As sementes foram imersas por $48 \mathrm{~h}$ à temperatura ambiente e ao abrigo da luz na solução alcoólica (metanol $\mathrm{HCl} 1 \%$ ), em proporção correspondente ao volume de mosto das bagas (González-Neves et al., 2004), e os compostos fenólicos solúveis foram determinados pelo método de Folin-Ciocalteau (Amerine \& Ough, 1980).

O teor de potássio foi determinado por fotometria de chama após digestão nítrico-perclórica das bagas (Malavolta et al., 1997). Os valores foram expressos em grama de potássio por quilo de baga com base em uma curva-padrão de potássio.

Os ácidos tartárico e málico foram determinados a partir do mosto diluído em água deionizada. Uma alíquota de $10 \mu \mathrm{L}$ foi injetada em cromatógrafo líquido Hewlett-Packard, modelo 1100, equipado com coluna SupelcoGel C-610H (Supelco, $30 \mathrm{~cm} \times 7,8 \mathrm{~mm}$ ) ajustada a uma temperatura de $15^{\circ} \mathrm{C}$, e detector arranjo de diodos (DAD) a $245 \mathrm{~nm}$. Foi realizada uma corrida isocrática a um fluxo de 0,5 $\mathrm{mL} \cdot \mathrm{min}^{-1}$, utilizando solução de ácido fosfórico a $0,5 \%$ como fase móvel.

Os açúcares foram extraídos da baga em três lavagens sucessivas com etanol a $80 \%(\mathrm{v} / \mathrm{v})$ a $80^{\circ} \mathrm{C}$. Os extratos foram centrifugados a 10.000 rpm por 10 minutos, e os sobrenadantes, reunidos em balão volumétrico de $10 \mathrm{~mL}$. Uma alíquota de $1 \mathrm{~mL}$ foi evaporada a vácuo em sistema SpeedVac (Savant, Co.). O volume foi reconstituído com água deionizada, e os açúcares solúveis, analisados por HPLC-PAD (Dionex, Sunnyvale, CA, USA) em um cromatógrafo DX-500, utilizando uma coluna CarboPac PA1 (Dionex, 4,0 x 250mm) acoplado a um detector de pulso amperométrico, em corrida isotérmica a $25^{\circ} \mathrm{C}$. Como fase móvel, foi utilizado $\mathrm{NaOH} 18 \mathrm{mM}$ em fluxo isocrático de $1 \mathrm{~mL} \cdot \mathrm{min}^{-1}$.

Todas as análises foram realizadas em triplicata, e os resultados, submetidos à análise de variância, pelo programa SAEG - versão 9.1.

\section{RESULTADOS E DISCUSSÃO}

Embora as variáveis climáticas apresentadas na Tabela 1 sejam semelhantes, pode-se verificar que as temperaturas máxima e mínima de Cordislândia são ligeiramente superiores às de Caldas. Desta forma, espera-se que o efeito do clima regional, associado às características do solo de cada região, afete a maturação e a composição das uvas, influenciando diretamente na qualidade da bebida. Este princípio determina o efeito do "terroir" empregado pelos franceses, em que reside o princípio da indicação geográfica para caracterização da tipicidade dos vinhos de qualidade.

A Figura 1 ilustra as condições climáticas observadas nas safras agrícolas de 2007 e 2008 nos municípios de Caldas e de Cordislândia.

As bagas das cultivares Chardonnay e Pinot Noir apresentaram menor acidez e maior teor de sólidos solúveis totais durante o amadurecimento, quando cultivadas em Cordislândia (Figura 2). As uvas cultivadas nesta região apresentaram maturação antecipada em relação às cultivadas em Caldas. Para a cultivar Chardonnay, os teores de sólidos solúveis foram praticamente os mesmos por ocasião da colheita nas duas safras, mas a acidez total foi significativamente inferior nas uvas cultivadas em Cordislândia.

Cordislândia, por estar localizada a uma altitude menor, apresenta temperaturas máximas e mínimas em torno de $3^{\circ} \mathrm{C}$ superior a Caldas (Figura 1). As temperaturas ambientais mais elevadas contribuem decisivamente para maior degradação do ácido málico das bagas (Toda, 1991; Conde et al., 2007).

Na safra de 2008, observou-se maior teor de sólidos solúveis e teores de acidez semelhantes aos obtidos na safra de 2007. O ano de 2007 apresentou maior índice pluviométrico, o que levou a maior retenção de umidade pelas bagas com consequente diluição dos açúcares e dos ácidos (Tabelas 2 e 3 ).

Nas duas safras avaliadas, os frutos colhidos em Caldas apresentaram maior tamanho e massa das bagas, o que parece estar relacionado ao maior acúmulo de umidade nas bagas cultivadas nesta região quando comparadas com as bagas colhidas em Cordislândia. Apesar de apresentarem precipitações semelhantes (1.222 mm em Cordislândia e 1.198,8 $\mathrm{mm}$ em Caldas acumulados nos meses de novembro de 2006, dezembro de 2006 e janeiro de 2007), a temperatura média observada em Cordislândia $(24,7$ $\left.{ }^{\circ} \mathrm{C}\right)$ foi superior à de Caldas $\left(19,8^{\circ} \mathrm{C}\right)$, o que deve ter favorecido a maturação e a evapotranspiração das bagas. 
De acordo com Dreier et al. (2000), a evapotranspiração parece ser a principal força propulsora do acúmulo de açúcares nas bagas em maturação. Consequentemente, bagas com diâmetro menor tendem a acumular mais açúcares do que as bagas maiores nas mesmas condições climáticas, devido à maior área exposta à evapotranspiração. $\mathrm{Na}$ safra de 2008, o índice pluviométrico foi menor nas duas regiões produtoras (Figura 1). As uvas colhidas nesta safra apresentaram teor de acidez total um pouco superior ao observado na safra anterior e conteúdo de sólidos solúveis significativamente superior, indicando o efeito da desidratação das bagas na concentração do mosto e acúmulo de açúcares (Tabela 2).

As condições climáticas da região de Cordislândia favoreceram a maturação das bagas. Nas duas safras avaliadas, os frutos colhidos em Cordislândia apresentaram maior $\mathrm{pH}$, menor teor de acidez titulável, relação glicose:frutose inferior a 1 e maior degradação do ácido málico e compostos fenólicos totais nas sementes. A razão entre os teores dos ácidos tartárico e málico observada para a cultivar Chardonnay, nos dois locais de cultivo (aproximadamente 1,5 na safra de 2007 e 1,1 na safra de 2008), está dentro do intervalo $(0,8-1,8)$ observado por Rizzon \& Sganzerla (2007) no mosto desta uva cultivada em Bento Gonçalves, na safra de 2004.

Johnson \& Nagel (1976) observaram maior teor de ácido málico em relação ao ácido tartárico nas bagas da cultivar Chardonnay, no final do período de mudança de coloração das bagas. Durante o amadurecimento, houve acentuada degradação do ácido málico sendo observada uma relação tartárico:málico de 1,4 no fruto maduro. Embora haja algumas tentativas de utilizar a relação tartárico:málico como índice de maturação, esta relação é muito variável entre as variedades, manejo e safras. Regiões frias produzem uvas com maior concentração de ácido málico. Segundo Conde et al. (2007), a relação inversa da temperatura com os teores de ácido málico ocorre devido ao efeito da temperatura no balanço entre síntese e degradação deste ácido. Nos vinhedos avaliados neste trabalho, o maior teor de ácido málico obtido nas uvas cultivadas em Caldas parece estar relacionado às temperaturas mais amenas desta região. Esta característica, entretanto, é favorável à elaboração do vinho espumante, uma vez que o teor de acidez contribui para a qualidade organoléptica da bebida.

O teor de potássio foi determinado na safra de 2008 para verificar se o aumento do $\mathrm{pH}$ observado nas bagas colhidas em Cordislândia estava relacionado à maior absorção de potássio pelas plantas ou pela maior degradação dos ácidos orgânicos. Os resultados sugerem efeito da degradação dos ácidos (Tabelas 2 e 3). Fogaça et al. (2007) acompanharam a absorção de potássio durante o amadurecimento das uvas 'Cabernet Sauvignon', 'Pinot Noir' e 'Merlot' em vinhedos localizados em Itaara (RS). Os autores observaram elevação do $\mathrm{pH}$ concomitante ao aumento na absorção de potássio nas fases iniciais do amadurecimento. Entretanto, nos frutos maduros, o teor de $\mathrm{pH}$ foi dependente da concentração da acidez titulável.

Embora na elaboração do espumante as uvas sejam vinificadas sem a casca, o conhecimento dos teores de compostos fenólicos pode contribuir na tomada de decisão pela elaboração de bebidas mais encorpadas, além de estarem envolvidos em reações de oxidação do vinho (Mané et al., 2007).

Neste experimento, observou-se maior acúmulo de antocianinas e compostos fenólicos na safra de 2008, nas duas regiões e cultivares avaliadas. A ocorrência de maior número de dias nublados em 2007 pode ter contribuído para o menor acúmulo destes flavonoides.

Os taninos da casca são sintetizados nos estágios iniciais do desenvolvimento da baga e apresentam pouca alteração em relação à quantidade por baga no período de mudança de cor das bagas e a colheita. Nas variedades tintas, as antocianinas acumulam-se nas cascas a partir do início da maturação e apresentam comportamento típico de produtos finais, apresentando pouca alteração após sua formação. Os taninos das sementes, por outro lado, decrescem durante o amadurecimento e escurecimento das sementes, provavelmente devido a reações de oxidação (Conde et al., 2007).

A cultivar Pinot Noir mostrou-se bastante suscetível às podridões da uva madura, amarga e ácida. Nas safras avaliadas, não atingiu níveis satisfatórios de amadurecimento, principalmente nas condições climáticas de Caldas. No ano de 2007, as bagas apodreceram antes de atingir padrões mínimos para colheita. Mesmo no ano de 2008, com condições climáticas mais favoráveis, as bagas de 'Pinot Noir' cultivadas em Caldas não completaram o amadurecimento, o que pode ser observado pelo elevado teor de ácido málico, baixo teor de sólidos solúveis e açúcares redutores, e elevada acidez (Tabela 3). Entretanto, as uvas colhidas em Cordislândia na safra de 2008 apresentaram acúmulo de sólidos solúveis superior aos valores observados por Peterlunger et al. (2002) em vinhedos conduzidos na Itália (média de $17,6^{\circ}$ Brix em quatro safras) e próximo aos valores observados por Marodin et al. (2006) nas 
safras de $2003\left(20,2^{\circ}\right.$ Brix $)$ e $2004\left(18,1^{\circ}\right.$ Brix $)$ em Garibaldi (RS). O teor de acidez titulável (8,5 g.L $\left.\mathrm{L}^{-1}\right)$ foi superior ao observado por Peterlunger et al. (2002) $\left(6,8\right.$ g.L $\left.\mathrm{L}^{-1}\right)$, porém inferior aos valores observados em
Garibaldi (9,5 g.L - $^{-1}$ em 2003 e 12,0 g.L - $^{-1}$ em 2004), o que indica potencial de produção com padrões satisfatórios de amadurecimento desta cultivar em Cordislândia.

TABELA 1 - Localização geográfica e dados climáticos dos municípios de Caldas e Cordislândia, situadas ao sul do Estado de Minas Gerais.

\begin{tabular}{lcc}
\hline Localização / Variável climática & Caldas & Cordislândia \\
\hline Latitude & $21^{\circ} 55^{\prime} \mathrm{S}$ & $21^{\circ} 40^{\prime} \mathrm{S}$ \\
Longitude & $46^{\circ} 23^{\prime} \mathrm{O}$ & $45^{\circ} 55^{\prime} \mathrm{O}$ \\
Altitude & $1.150 \mathrm{~m}$ & $873 \mathrm{~m}$ \\
Temperatura máxima do $\operatorname{ar}\left({ }^{\circ} \mathrm{C}\right)$ & 25,1 & 26,9 \\
Temperatura mínima do $\operatorname{ar}\left({ }^{\circ} \mathrm{C}\right)$ & 12,1 & 14,3 \\
Amplitude térmica diária $\left({ }^{\circ} \mathrm{C}\right)$ & 13,0 & 12,6 \\
Umidade relativa do ar $(\%)$ & 76,8 & 72,3 \\
Precipitação pluviométrica $(\mathrm{mm})$ & 1.500 & 1.300 \\
Insolação total mensal (horas) & 1.949 & 2.050 \\
\hline
\end{tabular}

Fonte: Tonietto et al. (2006).

TABELA 2 - Composição físico-química das bagas da cultivar Chardonnay colhida nos municípios de Caldas e de Cordislândia-MG, nas safras de 2007 e 2008.

\begin{tabular}{|c|c|c|c|c|}
\hline \multirow[b]{2}{*}{ Variável } & \multicolumn{2}{|l|}{2007} & \multicolumn{2}{|l|}{2008} \\
\hline & Caldas & Cordislândia & Caldas & Cordislândia \\
\hline Diâm.transv. (mm) & $15,45 \pm 0,86 \mathrm{~A}$ & $14,35 \pm 1,10 \mathrm{~B}$ & $14,06 \pm 1,18 \mathrm{a}$ & $13,28 \pm 0,91 b$ \\
\hline Diâm.long. (mm) & $15,53 \pm 1,00 \mathrm{~A}$ & $14,76 \pm 1,15 \mathrm{~B}$ & $14,31 \pm 1,30 \mathrm{a}$ & $13,45 \pm 0,87 \mathrm{~b}$ \\
\hline Massa da baga (g) & $2,10 \pm 0,01 \mathrm{~A}$ & $1,75 \pm 0,01 \mathrm{~B}$ & $1,78 \pm 0,03 \mathrm{a}$ & $1,40 \pm 0,02 b$ \\
\hline $\mathrm{pH}$ & $3,14 \pm 0,01 \mathrm{~B}$ & $3,36 \pm 0,01 \mathrm{~A}$ & $3,26 \pm 0,02 b$ & $3,38 \pm 0,01 \mathrm{a}$ \\
\hline Acidez (meq. $\mathrm{L}^{-1}$ ) & $110,67 \pm 0,58 \mathrm{~A}$ & $98,67 \pm 2,52 \mathrm{~B}$ & $122,33 \pm 3,21 \mathrm{a}$ & $99,33 \pm 2,08 \mathrm{~b}$ \\
\hline Ác.tartárico (g.L $\left.\mathrm{L}^{-1}\right)$ & $4,84 \pm 0,05 \mathrm{~A}$ & $5,82 \pm 0,48 \mathrm{~A}$ & $5,75 \pm 0,05 \mathrm{a}$ & $3,78 \pm 0,61 b$ \\
\hline Ác.málico (g.L-1) & $3,21 \pm 0,18 \mathrm{~B}$ & $3,74 \pm 0,35 \mathrm{~A}$ & $5,21 \pm 0,16 \mathrm{a}$ & $3,66 \pm 0,26 \mathrm{~b}$ \\
\hline SST $\left({ }^{\circ}\right.$ Brix $)$ & $15,97 \pm 0,15 \mathrm{~B}$ & $16,87 \pm 0,12 \mathrm{~A}$ & $19,73 \pm 0,15 \mathrm{a}$ & $19,67 \pm 0,29 \mathrm{a}$ \\
\hline Glicose (mg.g baga $\left.{ }^{-1}\right)$ & $54,70 \pm 5,10 \mathrm{~A}$ & $51,10 \pm 0,70 \mathrm{~B}$ & $80,70 \pm 9,80 \mathrm{a}$ & $84,20 \pm 5,30 \mathrm{a}$ \\
\hline Frutose (mg.g baga ${ }^{-1}$ ) & $44,00 \pm 2,60 \mathrm{~A}$ & $45,10 \pm 0,80 \mathrm{~A}$ & $64,50 \pm 7,70 b$ & $95,10 \pm 9,20 \mathrm{a}$ \\
\hline Sacarose (mg.g baga $\left.{ }^{-1}\right)$ & $0,70 \pm 0,20 \mathrm{~B}$ & $0,90 \pm 0,20 \mathrm{~A}$ & $1,80 \pm 0,40 \mathrm{a}$ & $1,80 \pm 0,30 \mathrm{a}$ \\
\hline $\begin{array}{l}\text { Fenólicos totais } \\
\left(\text { mg ác.gálico.g casca }{ }^{-1}\right)\end{array}$ & $6,35 \pm 0,16 \mathrm{~B}$ & $6,67 \pm 0,20 \mathrm{~A}$ & $9,14 \pm 0,67 \mathrm{a}$ & $7,16 \pm 0,18 b$ \\
\hline $\begin{array}{l}\text { Fenólicos totais } \\
\left.\text { (mg ác.gálico.g semente }{ }^{-1}\right)\end{array}$ & $86,65 \pm 4,01 \mathrm{~A}$ & $74,19 \pm 4,49 \mathrm{~B}$ & $102,25 \pm 2,65 \mathrm{a}$ & $91,51 \pm 3,26 b$ \\
\hline Potássio (g K.kg baga ${ }^{-1}$ ) & - & - & $2,53 \pm 0,34 \mathrm{a}$ & $2,66 \pm 0,13 \mathrm{a}$ \\
\hline
\end{tabular}

Dados representam valores médios de três repetições \pm desvio-padrão.

Letras diferentes na mesma linha (maiúscula para a safra de 2007 e minúscula para a safra de 2008) indicam que os dados diferem significativamente, pelo teste $\mathrm{F}$. 
TABELA 3 - Composição físico-química das bagas da cultivar Pinot Noir colhida nos municípios de Caldas e de Cordislândia-MG, nas safras de 2007 e 2008.

\begin{tabular}{|c|c|c|c|c|}
\hline \multirow[b]{2}{*}{ Variável } & 2007 & \multicolumn{3}{|c|}{2008} \\
\hline & Caldas* & Cordislândia & Caldas & Cordislândia \\
\hline Diâm.transv. (mm) & $14,71 \pm 1,36 \mathrm{~A}$ & $13,69 \pm 1,01 \mathrm{~B}$ & $14,00 \pm 1,16 \mathrm{a}$ & $13,21 \pm 1,22 b$ \\
\hline Diâm.long. (mm) & $15,23 \pm 1,15 \mathrm{~A}$ & $14,37 \pm 1,24 \mathrm{~B}$ & $14,85 \pm 1,17 \mathrm{a}$ & $13,56 \pm 1,11 b$ \\
\hline Massa da baga (g) & $1,81 \mathrm{~A}$ & $1,54 \pm 0,12 \mathrm{~B}$ & $1,59 \pm 0,01 \mathrm{a}$ & $1,43 \pm 0,03 \mathrm{~b}$ \\
\hline $\mathrm{pH}$ & $3,09 \pm 0,03 \mathrm{~B}$ & $3,26 \pm 0,02 \mathrm{~A}$ & $3,17 \pm 0,01 \mathrm{~b}$ & $3,36 \pm 0,01 \mathrm{a}$ \\
\hline Acidez (meq.L-1) & $147,33 \pm 5,03 \mathrm{~A}$ & $122,00 \pm 4,36 \mathrm{~B}$ & $149,33 \pm 3,79 \mathrm{a}$ & $113,00 \pm 2,00 b$ \\
\hline Ác.tartárico (g.L $\left.{ }^{-1}\right)$ & $5,92 \pm 0,60 \mathrm{~A}$ & $5,15 \pm 0,06 \mathrm{~B}$ & $5,59 \pm 0,14 \mathrm{a}$ & $4,65 \pm 0,37 b$ \\
\hline Ác.málico (g.L-1) & $7,74 \pm 0,21 \mathrm{~A}$ & $6,01 \pm 0,17 \mathrm{~B}$ & $8,04 \pm 0,39 \mathrm{a}$ & $4,45 \pm 0,14 b$ \\
\hline SST $\left({ }^{\circ}\right.$ Brix $)$ & $13,63 \pm 0,23 \mathrm{~B}$ & $16,07 \pm 0,38 \mathrm{~A}$ & $16,47 \pm 0,06 \mathrm{~b}$ & $19,30 \pm 0,06 \mathrm{a}$ \\
\hline Glicose (mg.g baga ${ }^{-1}$ ) & - & $45,90 \pm 1,00$ & $60,00 \pm 1,60 b$ & $88,10 \pm 3,30 \mathrm{a}$ \\
\hline Frutose (mg.g baga ${ }^{-1}$ ) & - & $37,40 \pm 1,30$ & $47,30 \pm 0,90 b$ & $92,10 \pm 3,20 \mathrm{a}$ \\
\hline Sacarose (mg.g baga ${ }^{-1}$ ) & - & $1,00 \pm 0,30$ & $1,40 \pm 0,40 \mathrm{a}$ & $1,80 \pm 0,90 \mathrm{a}$ \\
\hline $\begin{array}{l}\text { Antocianinas } \\
\left(\mathrm{mg} \text { malvidina.g casca }{ }^{-1}\right)\end{array}$ & - & $2,10 \pm 0,07$ & $3,54 \pm 0,08 \mathrm{a}$ & $3,07 \pm 0,09 \mathrm{~b}$ \\
\hline $\begin{array}{l}\text { Fenólicos totais } \\
\left(\text { mg ác.gálico.g casca }^{-1}\right)\end{array}$ & - & $11,55 \pm 0,48$ & $14,72 \pm 1,25 \mathrm{a}$ & $15,27 \pm 0,72 \mathrm{a}$ \\
\hline $\begin{array}{l}\text { Fenólicos totais } \\
\left(\text { mg ác.gálico.g semente }{ }^{-1}\right)\end{array}$ & - & $120,68 \pm 4,52$ & $120,83 \pm 5,20 \mathrm{a}$ & $112,41 \pm 7,12 b$ \\
\hline Potássio (g K.kg baga ${ }^{-1}$ ) & - & - & $2,45 \pm 0,38 \mathrm{a}$ & $2,61 \pm 0,13 \mathrm{a}$ \\
\hline
\end{tabular}

* Valores representam composição do mosto coletado no último dia de amostragem durante o amadurecimento.

Dados representam valores médios de três repetições \pm desvio-padrão.

Letras diferentes na mesma linha (maiúscula para a safra de 2007 e minúscula para a safra de 2008) indicam que os dados diferem significativamente, pelo teste $\mathrm{F}$.

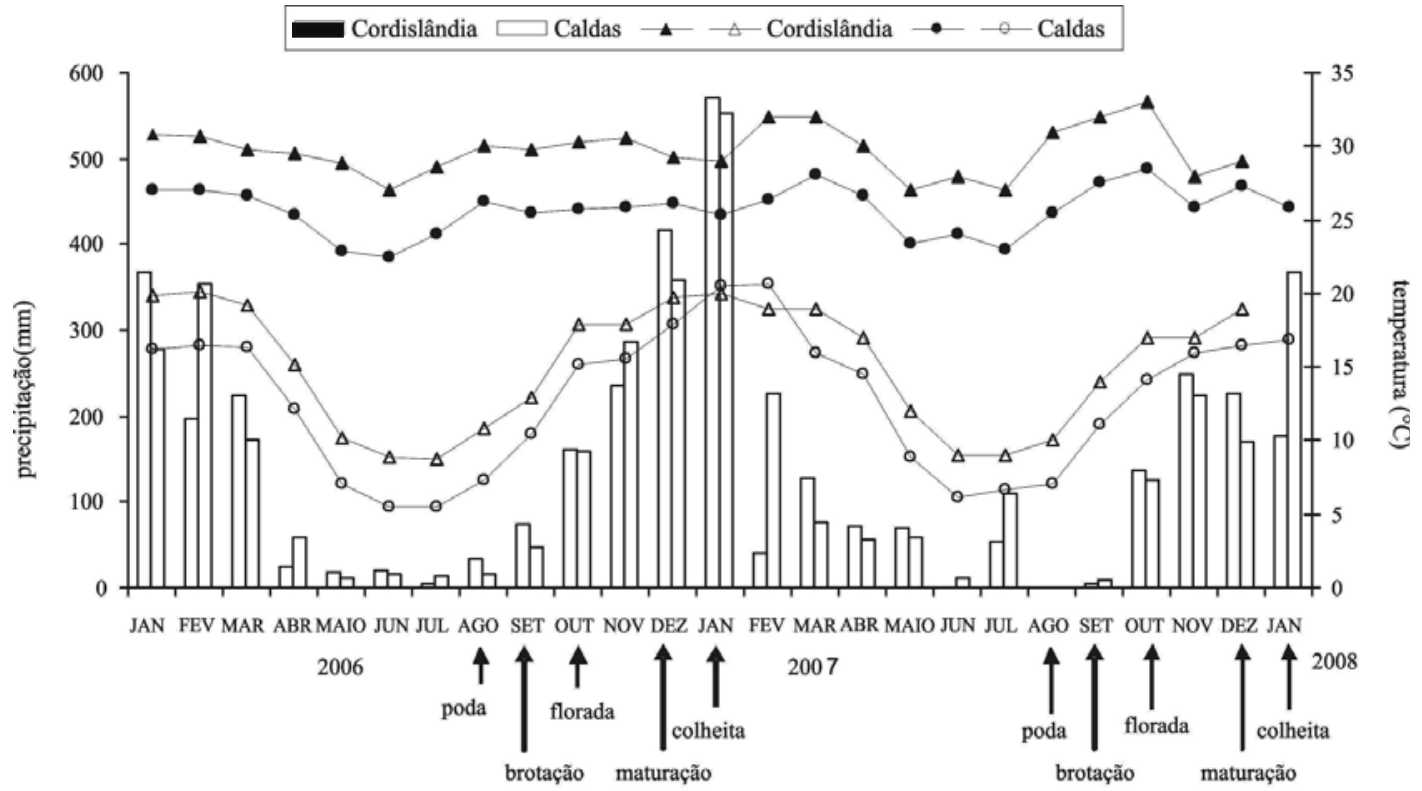

FIGURA 1 - Fenologia da videira, precipitação mensal e temperaturas máximas e mínimas observadas durante o desenvolvimento das cultivares Chardonnay e Pinot Noir nas safras agrícolas de 2007 e 2008, nos municípios de Caldas-MG, e Cordislândia-MG. 
'Chardonnay'
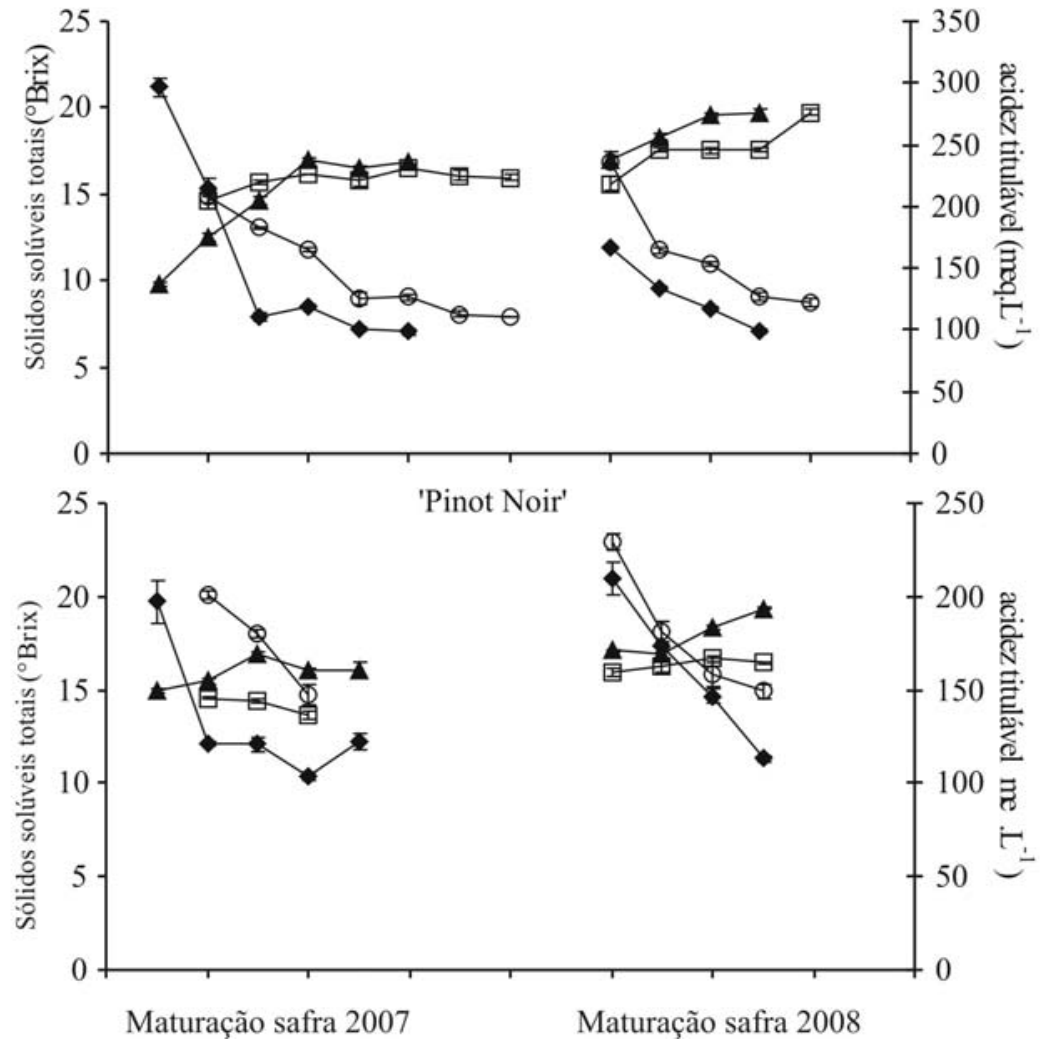

FIGURA 2 - Teores de sólidos solúveis totais ( ${ }^{\circ}$ Brix) e acidez total titulável (meq. $\mathrm{L}^{-1}$ ) durante o amadurecimento das bagas das videiras Chardonnay e Pinot Noir, nas safras de 2007 e 2008.

\section{CONCLUSÕES}

1- A temperatura ambiental mais elevada no município de Cordislândia contribui para maior degradação do ácido málico e maior acúmulo de sólidos solúveis das bagas.

2- A cultivar Pinot Noir não alcança índices de maturação satisfatórios no município de Caldas.

3- A maior altitude de Caldas influencia no melhor equilíbrio entre sólidos solúveis e acidez total das uvas 'Chardonnay'.

\section{AGRADECIMENTOS}

Os autores agradecem à FAPEMIG e ao CNPq, pelo auxílio financeiro e concessão de bolsas; às empresas Vitacea e Fazenda do Porto, pela parceria na condução dos vinhedos, e ao Dr. Marcos Roberto Lopes do Nascimento, por autorizar a utilização das instalações da Comissão Nacional de Energia Nuclear (CNEN - Poços de Caldas) para a realização da digestão nitroperclórica das bagas.

\section{REFERÊNCIAS}

AMERINE, M.A.; OUGH, C.S. Methods for analysis of musts and wines. New York: John Wiley \& Sons, 1980. 341p.

BERGQVIST, J.; DOKOOZLIAN, N.; EBISUDA, N. Sunlight Exposure and Temperature Effects on Berry Growth and Composition of Cabernet Sauvignon and Grenache in the Central San Joaquin Valley of California. American Journal of Enolology \& Viticulture, Davis, v. 52, n. 1, p. 1-7, 2001.

CONDE, C.; SILVA, P.; FONTES, N.; DIAS, A.C.P.; TAVARES, R.M.; SOUSA, M.J.; AGASSE, A.; DELROT, S.; GERÓS, H. Biochemical changes throughout grape berry development and fruit and wine quality. Food, Ikenobo, v.1., n.1, p.1-22, 2007.

DREIER, L.P.; STOLL, G.S.; RUFFNER, H.P. Berry ripening and evapotranspiration in Vitis vinifera $\mathrm{L}$ American Journal of Enolology \& Viticulture, Davis, v.51, n.4, p.340-346, 2000. 
FOGAÇA, A.O.; DAUDT, C.E.; DORNELES, F. Potássio em uvas II - Análise peciolar e sua correlação com o teor de potássio em uvas viníferas. Ciência e Tecnologia de Alimentos, Campinas, v.27, n.3, p.597-601, 2007.

GIUSTI, M.M.; WROSLTAD, R.E. Characterization and measurement of anthocyanins by uv-visible spectroscopy: current protocols in food analytical chemistry. New York: John Willey \& Sons, 2000.

GONZÁLEZ-NEVES, G.; CHARAMELO, D.; BALADO, J.; BARREIRO, L.; BOCHICCHIO, R.; GATTO, G.; GIL, G.; TESSORE, A.; CARBONNEAU, A.; MOUTOUNET, M. Phenolic potencial of Tannat, Cabernet Sauvignon and Merlot grapes and their correspondence with wine composition. Analytica Chimica Acta, Amsterdam, v.513, n.1, p.191-196, 2004.

JACKSON, D.I.; LOMBARD, P.B. Environmental and management practices affecting grape composition and wine quality - a review. American Journal of Enolology \& Viticulture, Davis, v.44, n.4, p.409430, 1993.

JOHNSON, T.; NAGEL, C.W. Composition of central Washington grapes during maturation. American Journal of Enolology \& Viticulture, Davis, v.27, n.1, p.15-25, 1976.

MALAVOLTA, E.; VITTI, G.C.; OLIVEIRA, S.A. Metodologia para análise de elementos em material vegetal. In: Avaliação do estado nutricional das plantas: princípios e aplicações. 2.ed. Piracicaba: POTAFÓS, 1997. cap.6, p.231-307.

MANÉ, C.; SOUQUET, J.M.; OLLÉ, D. ; VERRIÉS, C. ; VÉRAN, F. ; MAZEROLLES, G. ; CHEYNIER, V. ; FULCRAND, H. Optimization of simultaneous flavanol, phenolic acid, and anthocyanin extraction from grapes using an experimental design: application to the characterization of Champagne grape varieties. Journal of Agricultural and Food Chemistry, Easton, v.55, n.18, p.7224-7233, 2007.
MARODIN, G.A.B.; GUERRA, D.S.; ZANINI, C.L.D.; ARGENTA, F.; GRASSELLI, V. Brotação e produção das videiras 'Cabernet Sauvignon' e 'Pinot Noir' submetidas a diferentes concentrações de cianamida hidrogenada. Revista Brasileira de Fruticultura, Jaboticabal, v.28, n.3, p.406-409, 2006.

PETERLUNGER, E.; CELOTTI, E.; DA DALT, G.; STEFANELLI, S.; GOLLINO, G.; ZIRONI, R. Effect of training system on Pinot Noir grape and wine composition. American Journal of Enology and Viticulture, Davis, v.53, n.1, p.14-18, 2002.

PROTAS, J.F.S.; CAMARGO, U.A.; MELLO, L.M.R. Vitivinicultura brasileira: regiões tradicionais e polos emergentes. Informe Agropecuário, Belo Horizonte, v.27, n.234, p.7-15, 2006.

REGINA, M.A.; ALVARENGA, A.A.; CHALFUN, N.N.J.; CHALFUN JÚNIOR, A. Levantamento nutricional e diagnóstico agronômico dos vinhedos de Caldas. Revista Brasileira de Fruticultura, Cruz das Almas, v.20, n.1., p.15-20, 1998.

RIZZON, L.A.; SGANZERLA, V.M.A. Ácidos tartárico e málico no mosto de uva em Bento Gonçalves-RS. Ciência Rural, Santa Maria, v.37, n.3, p.911-914, 2007.

SILVA, T.G. Diagnóstico vitivinícola do Sul de Minas Gerais. 1998. 196 f. Dissertação (Mestrado - Fitotecnia) - Universidade Federal de Lavras, Lavras, 1998.

TODA, F.M. Biologia de la vid: fundamentos biológicos de la viticultura. Madrid: Ed. Mundi-Prensa, 1991. 346p.

TONIETTO, J.; VIANELLO, R.L.; REGINA, M.A. Caracterização macroclimática e potencial enológico de diferentes regiões com vocação vitícola em Minas Gerais. Informe Agropecuário, Belo Horizonte, v. 27, n. 234, p. 32-55, 2006. 